Wenliang Guo, Daqiang Cang*, Lingling Zhang* and Junxiang Guo

\title{
Mechanism of recovery processes for rare earth and iron from Bayan Obo tailings
}

https://doi.org/10.1515/ijcre-2020-0077

Received May 4, 2020; accepted September 4, 2020; published online September 21, 2020

\begin{abstract}
Rare earth (RE) and iron minerals in tailings exhibit fine embedded granularity and are closely associated with silicates, carbonates, and other lode minerals, which are difficult to be recycled. Studies of these tailings led to some new processes of ore dressing, involving grinding, RE flotation, strong magnetic separation, and positive iron flotation. In this closed circuit process, RE and iron minerals were separated after grinding, and the materials resulted from the flotation of small-sized $\mathrm{RE}$ and iron mineral particles were accurately controlled using a combination of inhibitors, dispersants, $\mathrm{pH}$ regulators, and collector agents. The ore dressing were ground to a fineness of $0.045 \mathrm{~mm}$, which was a process accounting for $95.6 \%$ of the material. The amount of water glass, NXJ (a combination of sodium carbonate mixed with a fine mud dispersant), and BGH (hydroxamic acid collector, a combination of 3-carboxy-2-naphthylhydroxamic acid and C59 hydroxamic acid) used in the primary separation of RE were $2.4 \mathrm{~kg} / \mathrm{t}, 2.5 \mathrm{~kg} / \mathrm{t}$, and $2.4 \mathrm{~kg} / \mathrm{t}$, respectively. The dosages of ammonium fluorosilicate and GXY (fatty acid collector, a combination of sodium oleate mixed with oxidized paraffin soap) used with iron coarse were $2.2 \mathrm{~kg} / \mathrm{t}$ and $1.2 \mathrm{~kg} / \mathrm{t}$, respectively. The RE collectors achieved chemical separation of $\mathrm{Ce}$, La, and other particles and formed stable five-membered cyclic chelates. Consequently, through the closed circuit experiment, the RE grade and recovery rate in the $\mathrm{RE}$ concentrate were improved to 50.3 and $61.6 \%$, respectively. The total iron (TFe) grade and recovery rate in the TFe concentrate were improved to 64.0 and $30.0 \%$, respectively, and other useful metals were also enriched; this process managed
\end{abstract}

*Corresponding authors: Daqiang Cang, School of Metallurgical and Ecological Engineering, University of Science \& Technology Beijing, Beijing 100083, PR China, E-mail: cdqlsustb@163.com; and Lingling Zhang, School of Energy and Environment Engineering, University of Science and Technology Beijing, Beijing 100083, PR China, E-mail: linglingzhangll@hotmail.com

Wenliang Guo and Junxiang Guo, School of Metallurgical and Ecological Engineering, University of Science \& Technology Beijing, Beijing 100083, PR China, E-mail: guowenliang201@163.com (W. Guo), q.qguo@163.com (J.Guo) secondary recycling of $\mathrm{RE}$ and $\mathrm{TFe}$ possible, leading to improvements in resource utilization.

Keywords: flotation; iron recycle; magnetic separation; rare earth recycle; tailings.

\section{Introduction}

The Bayan Obo mine is a large-scale deposit mainly consisting of iron ore and rare earth (RE), and the quantity of its $\mathrm{RE}$ reserves ranks first in the world. The RE minerals mainly consist of bastnaesite and monazite, and the percentages of cerium and lanthanum are 50.0 and $30.0 \%$, respectively (Abaka-Wood, Addai-Mensah, and Skinner 2018a; AbakaWood et al. 2019a; Abaka-Wood et al. 2018b; Abaka-Wood et al. 2019b; Abaka-Wood et al.2019c). At present, recovery of RE in tailings is achieved after iron dressing with weak magnetic picking, strong magnetic picking, and reverse flotation methods. Because of the applications of stage grinding and magnetic separation processes to iron ore dressings, the size distribution in the tailings is relatively large; this increases the difficulty in RE recovery. The proportion of RE in tailings is about 3.0 to $4.0 \%$, which represent a considerable waste of RE minerals. Conversely, the percentage of TFe is approximately $15.0 \%$, but the iron particles are fine-grained and they combine with silicates and carbonates; this results in considerable difficulty in the recovery of iron from tailings (Avazpour et al. 2019; Jordens, Cheng, and Waters 2013).

Only a few RE minerals and iron minerals are distributed in the tailings (Zheng, Wu, and Bian 2017a; Zheng, Bian, and Wu 2017b). It is necessary to grind the Bayan Obo tailings to separate the majority of RE and iron mineral monomers. Grinding results in increased quantity of fine mud, which produces considerable amount of the slime, and it is challenging to control the dispersion of pulp during flotation (Kursun, Terzi, and Ozdemir 2019; Lan et al. 2019; Marion, Li, and Waters 2020). The flotation method is generally adopted in the processing of RE minerals, and the best method for recovering hematite involves a sequence of gravity separation, flotation, and magnetic separation. To ensure a high recovery rate from RE concentrates, the recovery of RE minerals must focus on the recovery of fine-grained RE minerals and rich intergrowths. 
Simultaneously, it is essential to reduce the loss of RE minerals in the tailings to the maximum extent as possible (Owens et al. 2019; Ren et al. 1997; Sarswat et al. 2020). Therefore, the selection of highly efficient reagent combinations is crucial for achieving success in RE flotation.

The RE in iron ore tailings is recycled with flotation processes using combinations of inhibitors such as water glass and 8\# (Naphthalene hydroxamic acid) RE collector. Since it has been approved for production processes, the recovery rate for RE using this process is very low, and it is ineffective for recycling RE minerals found as fine particles. As the annual production of Bayan Obo tailings exceeds 3.5 million metric tons, the secondary recovery of $\mathrm{RE}$ and $\mathrm{TFe}$ from the tailings of Bayan Obo mine is of considerable importance. Therefore, this study focuses on the processes for dressing RE tailings, the use of effective reagent regimens, the comprehensive recycling of $\mathrm{RE}$ and $\mathrm{TFe}$, and the development of critical technical processes for effective utilization of fine grain, complex, and secondary RE and TFe resources.

\section{Experimental section}

\subsection{Raw material}

Target tailings were obtained from the Baotou Steel RE Dressing Plant. Bayan Obo tailings were packed after natural drying, crushing, mixing, and shrinkage. The chemical species of Bayan Obo Tailings were detected by X-ray fluorescence spectrometer (XRF, Axios, PANalytical B.V., Netherlands). From the analyzed results of the chemical compositions for samples in Table 1, the usefully recyclable minerals in the rare earth tailings were iron mineral and rare earth mineral. The total iron amount of the iron mineral was $15.5 \%$, while the amount of the oxidized rare earth was 3.9\%. The purities were mainly calcium oxide, silicon dioxide, barium oxide, and sodium oxide, etc. In order to further find out the phase composition of the useful minerals, the iron and mineral phase were separately analyzed, and the phase analyses results were summarized in Table 2 . The hematite accounted for $71.9 \%$ in iron minerals, the magnetite accounted for $12.5 \%$, the iron silicate accounted for $11.3 \%$, and the rest was pyrite (4.4\%). The rare earth minerals mainly included bastnaesite and monazite. The rare earth oxide accounted for $55.8 \%$ in the bastnaesite, while the rare earth oxide accounted for $44.2 \%$ in monazite. Besides, the gangue mineral mainly included augite and osannite, which accounted for $28.2 \%$ of the total mineral, and some of them were mica and fluorite, accounted for 14.6 and 15.6\%, respectively. The rest were agustite, quartz, feldspar, barite, and dolomite, etc.

\subsection{Experimental apparatus and reagents}

The apparatus used in this study included an XFD III single trough flotation machine (0.5 L/0.75 L/1.0 L) (Jilin Exploration Machinery Factory, Jiangxi, China), RK/ ZQMФ250 $\times 10$ ball mill (Wuhan Rock Powder Grinding Equipment Manufacturing Co., Ltd.), RK/ZL-Ф260/Ф200 disk vacuum filter (Wuhan Rock Powder Grinding Equipment Manufacturing Co., Ltd.), $\mathrm{pH}-3 \mathrm{C}$ precise $\mathrm{pH}$ meter (Shanghai Ray Magnetic Instrument Factory), and SLon500 high-intensity magnetic separator (Ganzhou Jinhuan magnetic separation equipment Co., Ltd.). Reagents used in this paper included sodium silicate (Baotou Steel Rare Earth Dressing Plant) and ammonium fluorosilicate (Hubei Xinrunde Chemical Industry Co., Ltd.).

\subsection{Experimental methods}

The small amount of iron existed in these Bayan Obo tailings, thus a strong magnetic separation process must be

Table 1: Chemical species analyses of Bayan Obo tailings (wt.\%).

\begin{tabular}{lrrrrrrrrrrrr}
\hline Species & TFe & REO & $\mathbf{C a O}$ & $\mathbf{S i O}_{\mathbf{2}}$ & $\mathbf{P}$ & $\mathbf{S}$ & $\mathbf{K}_{\mathbf{2}} \mathbf{O}$ & $\mathbf{N a}_{\mathbf{2}} \mathbf{O}$ & $\mathbf{F}$ & $\mathbf{M g O}$ & $\mathbf{A l}_{\mathbf{2}} \mathbf{O}_{\mathbf{3}}$ & $\mathbf{B a O}$ \\
\hline Content & 15.5 & 3.9 & 19.9 & 18.7 & 1.1 & 1.7 & 1.3 & 1.9 & 8.1 & 4.7 & 1.7 & 2.5 \\
\hline
\end{tabular}

Table 2: Phase analyses of iron and rare earth (RE) minerals (wt.\%).

\begin{tabular}{lrrrrrrr}
\hline & & \multicolumn{2}{c}{ Iron-bearing mineral } & & \multicolumn{2}{r}{ RE mineral } \\
\cline { 2 - 7 } Species & Hematite & Magnetite & Iron silicate & Pyrite & & Bastnaesite & Monazite \\
\hline Content & 71.88 & 12.5 & 11.3 & 4.4 & 55.8 & 44.2 \\
\hline
\end{tabular}




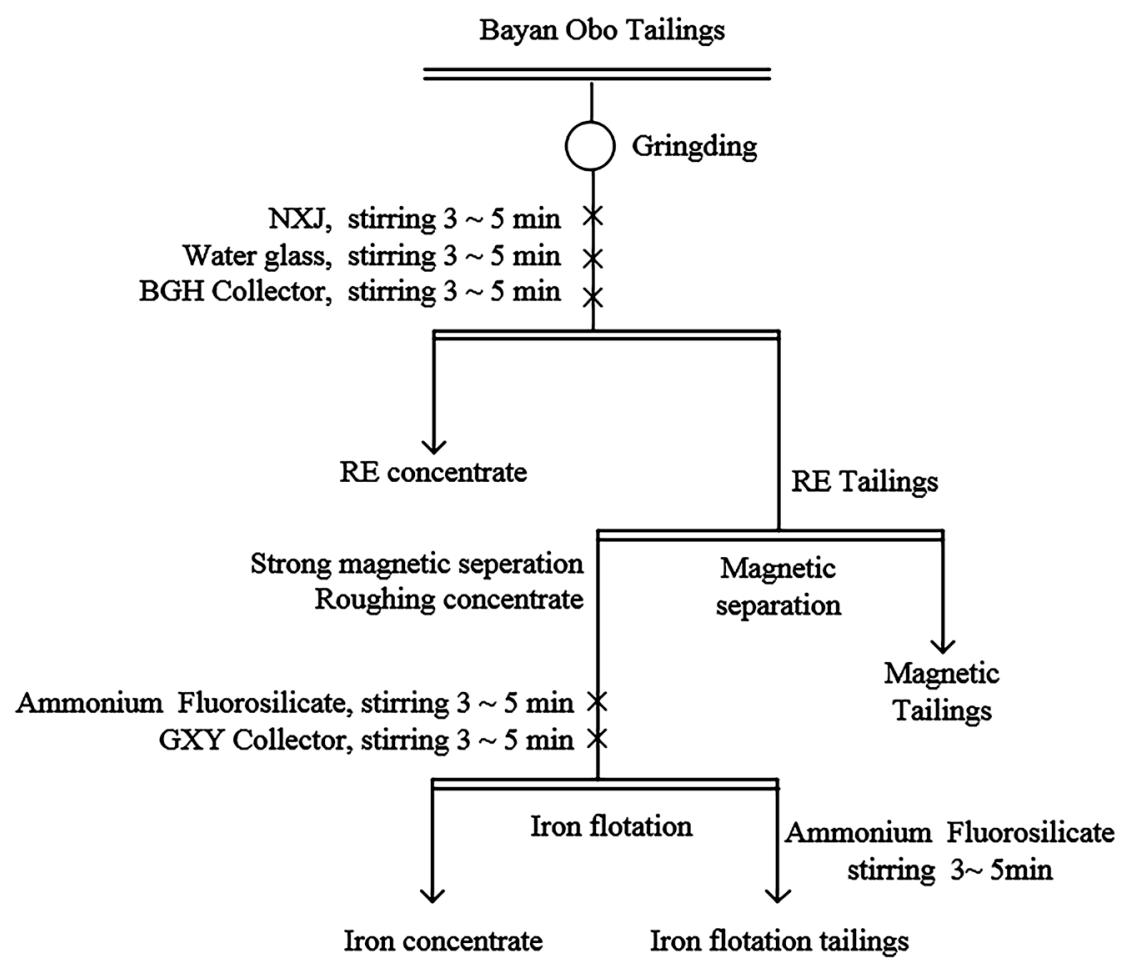

Figure 1: The flow chart for selecting the sample. used to recover the hematite. A flotation method was used to recover hematite after considerable enrichment of the hematite ore. Therefore, the test scheme adopted in this study included grinding, RE flotation, strong magnetic separation, and positive flotation. First, the Bayan Obo tailings were ground, and then the RE constituents were obtained by flotation. Iron concentration was obtained by positive flotation of iron from high-grade iron flotation, which were obtained from tailings and middling ore by a strong magnetic operation. RE mineral recovery will be suppressed when RE are floated in strong acid or strong alkali media; RE flotation was usually carried out in weakly alkaline or moderately alkaline pulp. Common RE flotation inhibitors included water glass, starch, carboxymethyl cellulose, sodium fluorosilicate, dextrin, and ammonium lignosulfonate. The commonly used RE flotation collectors were fatty acids, alkyl hydroxamic acid and naphthyl hydroxamic acid, and 3-hydroxy-2-naphthyl hydroxamic acid (Kulkarni and Somasundaran 1980; Yap et al. 1981). The selection of RE tailings as flotation feeds of RE; comparison tests of sodium carbonate, sodium hydroxide, water glass, modified starch, carboxymethyl cellulose, XJ (fine mud dispersant, a combination of sodium tripolyphosphate and dextrin), sodium fluorosilicate and other regulators; and comparison tests of alkyl hydroxamic acid, $\mathrm{H} 205$, and BGH collectors were carried out for determining the suitable $\mathrm{pH}$ regulator and appropriate concentrations of dispersant, inhibitor, and RE collector. The $\mathrm{pH}$ of pulp was 8.8 9.2, the mass concentration was $40 \% \sim 50 \%$, and the stirring speed was $1900 \mathrm{rpm}$. The flow chart for selecting the sample and the required chemicals and the investigations of their variable parameters were presented in Figure 1 and Table 3.

The preparation steps of the samples used in IR spectra and X-ray photoelectron spectrum: the bastnaesite was obtained from the lump ore with rich RE in Bayan Obo ore. The lump ore was first crushed below $0.18 \mathrm{~mm}$, and the bastnaesite was selected under the microscope. And they were ground slightly below $0.74 \mathrm{~mm}$, and were further divided into two parts. One was used as bastnaesite

Table 3: The required chemical dosage for each group of experiment.

\begin{tabular}{|c|c|c|c|}
\hline & $\begin{array}{l}\text { Types of flotation } \\
\text { reagents }\end{array}$ & $\begin{array}{l}\text { Reagent vari- } \\
\text { ables }(\mathrm{kg} / \mathrm{t})\end{array}$ & $\begin{array}{l}\text { Dosage of other chem- } \\
\text { icals }(\mathrm{kg} / \mathrm{t})\end{array}$ \\
\hline 1 & NXJ & $\begin{array}{r}1.5,2.0,2.5,3.0 \\
3.5\end{array}$ & BGH 2.0, water glass 2.5 \\
\hline 2 & Water glass & $\begin{array}{r}1.8,2.1,2.4,2.7 \text {, } 3.0\end{array}$ & BGH 2.0, NXJ 2.5 \\
\hline 3 & BGH & $\begin{array}{r}1.5,1.8,2.1,2.4 \\
2.7\end{array}$ & Water glass $2.4, \mathrm{NXJ} 2.5$ \\
\hline 4 & $\begin{array}{l}\text { Ammonium } \\
\text { fluorosilicate }\end{array}$ & $\begin{array}{r}1.8,2.0,2.2,2.4, \\
2.6\end{array}$ & GXY 1.2 \\
\hline 5 & GXY & 1.2 & $\begin{array}{l}\text { Ammonium fluo- } \\
\text { rosilicate } 2.2\end{array}$ \\
\hline
\end{tabular}


sample, while another was stirred homogenously with addition of 1.5 times distilled water, and was further added with $10 \%$ collectors BGH (the amount was $3 \mathrm{~kg} / \mathrm{t}$ ). The whole solution was stirred for $6 \mathrm{~min}$, and was further filtrated, and washed for 3-5 times, then it was finally dried, and further was used as bastnaesite sample after functioned with the collector BGH.

The testing contents of the IR spectra: the IR spectra was measured on 740-FTIR analyzer. Three kinds of samples were tested: the collectors $\mathrm{BGH}$, bastnaesite, and the bastnaesite after functioned with the collectors BGH. Through studying the position variations of the absorbing peaks for the main groups of the three kinds of samples, which kind of absorption of the collectors BGH on the bastnaesite could be determined.

The testing content of the XPS spectra: the XPS spectra were measured on K-Alpha1063X. Two kinds of samples were tested: bastnaesite and those bastnaesite after functioned with the collectors BGH. It could be further confirmed if the collectors BGH absorbed on the bastnaesite surface through investigating the peak intensity and binding energy variations of the two samples.

\section{Results and discussion}

\subsection{Effects of various factors on rare earth recovery}

\subsubsection{Influence of grinding fineness on RE flotation}

Particle size analyses are presented in Figure 2. The proportion of Bayan Obo tailings with size less than $0.074 \mathrm{~mm}$ is $89.8 \%$. The densities of RE minerals are higher for coarsesized particles. $51.2 \%$ of the RE minerals are distributed in particles with size greater than $0.061 \mathrm{~mm}, 77.6 \%$ are distributed in particles larger than $0.045 \mathrm{~mm}, 9.8 \%$ of particles is in the range from 0.025 to $0.045 \mathrm{~mm}$, and $12.6 \%$ of RE are distributed in particles with size less than $0.025 \mathrm{~mm}$. Particles with size greater than $0.045 \mathrm{~mm}$ are RE aggregates, whereas those with particle size less than $0.045 \mathrm{~mm}$ are $\mathrm{RE}$ aggregates closely integrated with sodium pyroxene, sodium amphibolite, fluorite, iron ore, and quartz; the smallest of these own sizes of $0.005 \mathrm{~mm}$. Particles smaller than $0.045 \mathrm{~mm}$ typically contain $48.3 \%$ iron ores, which are mainly in disseminated and inclusion form; the percentage range is narrow, and the iron ores are often integrated with sodium pyroxene, sodium amphibolite, fluorite, dolomite, and quartz. Overall, the RE and TFe separation should be made first in the secondary recovery; then refined RE and TFe

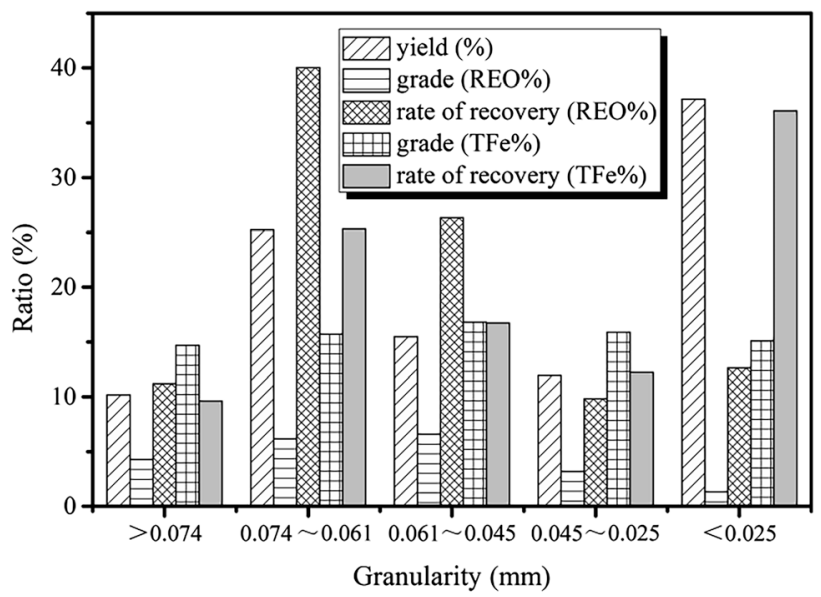

Figure 2: Particle-size analyses of Bayan Obo tailings.

concentrations can be obtained with the proper dressing procedures and reagents.

Test results for different grinding fineness are shown in Figure 3. With the gradual increase of grinding fineness, the dissociation degree of monomer of the RE mineral was also gradually increased, however, the coenobium became less and less. During the floatation process, the monomerdissociated RE mineral would flotation upward with the gas bubble, therefore the grade and recovery of the RE ore concentrate would gradually increase. When the grinding fineness was further increased to $-0.045 \mathrm{~mm}$, and it occupied $95.6 \%$, the grade and recovery of the RE ore concentrate reached the maximum. This was because the dissociation degree of RE achieved the highest value. Most of monomers of the RE were dissociated, and in the case of the relative well

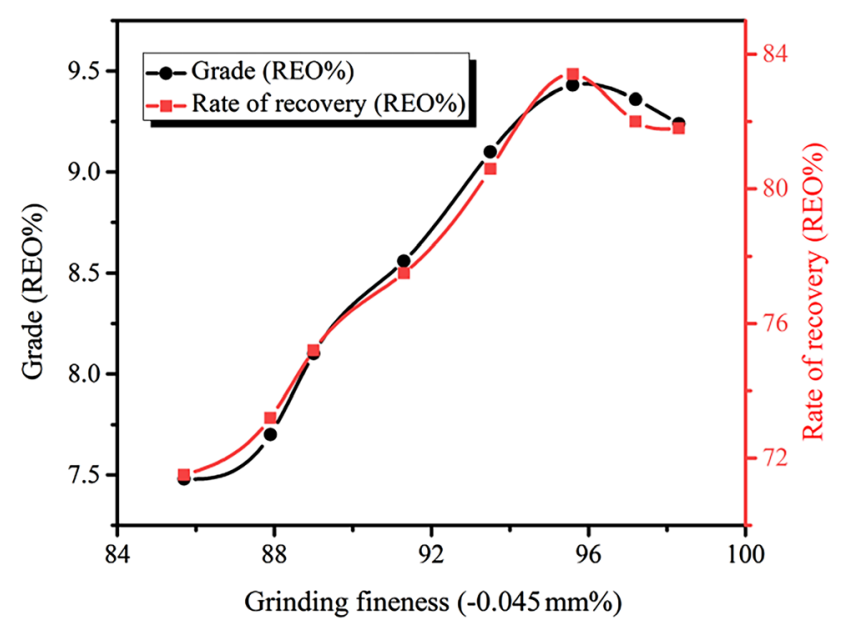

Figure 3: Relationship between different grinding fineness and RE coarse selection index (Conditions: compound collector BGH dosage of $2.0 \mathrm{~kg} / \mathrm{t}$, water glass dosage of $2.5 \mathrm{~kg} / \mathrm{t}$, and NXJ dosage of $2.0 \mathrm{~kg} / \mathrm{t}$ ). 
dispersion of ore pulp, the grade and recovery of the obtained RE ore concentrate were very high. When further increased the grinding fineness, although the RE mineral was continued dissociated, the mineral was over ground, which resulted in the increased amount of fine slit, and further affected the flotation index, finally resulted in decrease of the grade and recovery of the RE ore concentrate. Therefore, the following experiments all used the $0.045 \mathrm{~mm}$ (occupation of $95.6 \%$ ) grinding fineness as the best parameter.

\subsubsection{Influence of NXJ on the flotation separation index of RE}

$\mathrm{NXJ}$ is composed of sodium carbonate and $\mathrm{XJ}$, and the mass ratio of sodium carbonate and $\mathrm{XJ}$ is 6:1. The relationship between different NXJ dosages and RE coarse selection criteria is shown in Figure 4. The grade and recovery rate of $\mathrm{RE}$ coarse concentrates gradually increase with increasing amounts of NXJ in $1.5 \sim 3.0 \mathrm{~kg} / \mathrm{t}$ and $1.5 \sim 2.6 \mathrm{~kg} / \mathrm{t}$, and subsequently the grade and recovery rate reduce in $3.0 \sim 3.5 \mathrm{~kg} / \mathrm{t}$ and $2.6 \sim 3.5 \mathrm{~kg} / \mathrm{t}$. This is mainly due to an increase in the negative charge of the mineral particles on the surface caused by $\mathrm{XJ}$ and the resulting charge repulsion of mineral particles. Sodium carbonate can adjust the degrees of inhibitor and collector hydrolysis. Moreover, it controls the interactions between the collector and the mineral. The collector anion and hydroxide $\left(\mathrm{OH}^{-}\right)$can exhibit competitive adsorption on the mineral surface. When the $\mathrm{pH}$ value is high, the $\mathrm{OH}^{-}$concentration is also high. Consequently, the ability to retard the attraction of the collector anions and the mineral surface is enhanced. When the amount of NXJ is $2.5 \mathrm{~kg} / \mathrm{t}$, both the grade and

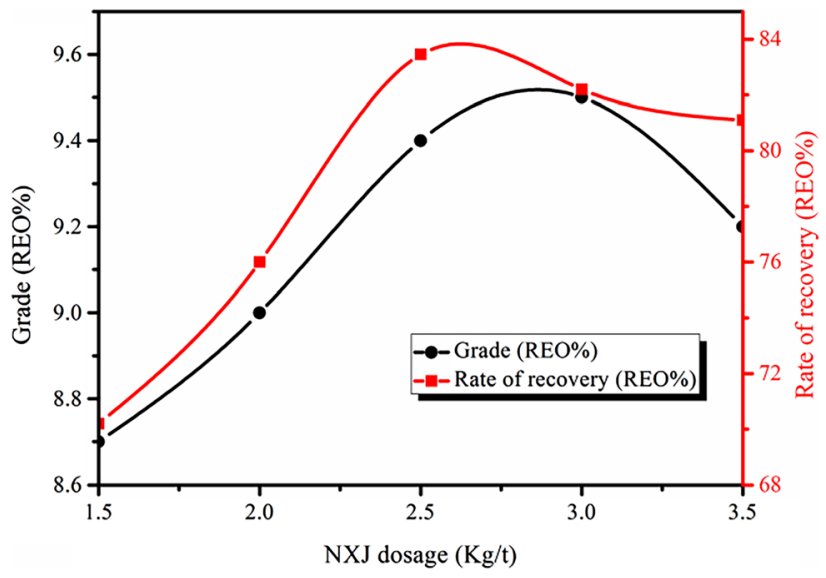

Figure 4: Relationship between NXJ amount and RE coarse selection index (Conditions: compound collector BGH dosage of $2.0 \mathrm{~kg} / \mathrm{t}$ and water glass dosage of $2.5 \mathrm{~kg} / \mathrm{t}$ ). recovery of RE coarse concentrates are high, and this dosage is therefore utilized in this study.

\subsubsection{Effect of water glass on RE separation index}

The relationship between water glass and RE coarse selection criteria is shown in Figure 5. With increased amounts of water glass, the inhibition of gangue minerals increased, the grade of $\mathrm{RE}$ coarse concentrate initially increased, and then it tended to remain stable. However, the recovery rate for RE coarse concentrates gradually decreased. It was mainly due to the gradually increasing dosage of water glass, the pulp $\mathrm{HSiO}_{3}{ }^{-}$and $\mathrm{H}_{2} \mathrm{SiO}_{3}$ concentration increased, and the two substances have very strong hydrophilicity, they were adsorbed on the minerals surface to make them hydrophilic. At the same time, the two substances adsorbed on the mineral surface was to prevent the collector adsorption, which made some of the $\mathrm{RE}$ minerals and gangue were restrained, resulting in declined recovery rate of the RE coarse concentrate. When the amount of water glass reached $2.4 \mathrm{~kg} / \mathrm{t}$, both the grade and recovery of RE coarse concentrates were enhanced, reaching 9.4 and $84.8 \%$, respectively. The further increase of water glass content increased the grade of REO, but the decrease of REO recovery rate was more obvious. For RE coarse concentrate, high recovery rate should be the optimum condition, therefore, the optimal concentration for the water glass is $2.4 \mathrm{~kg} / \mathrm{t}$.

\subsubsection{Effect of BGH collector on the selectivity of RE}

The BGH collector is a hydroxamic acid collector that can effectively recover fine grain grade RE minerals, and it also

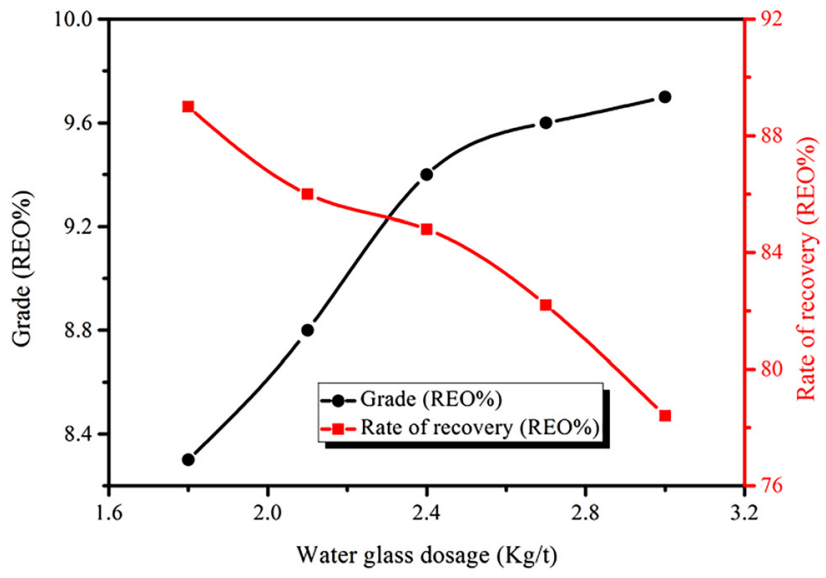

Figure 5: Relationship between the amount of water glass and RE coarse selection index (Conditions: collector BGH of $2.0 \mathrm{~kg} / \mathrm{t}$ and $\mathrm{NX}$ ) of $2.5 \mathrm{~kg} / \mathrm{t}$ ). 


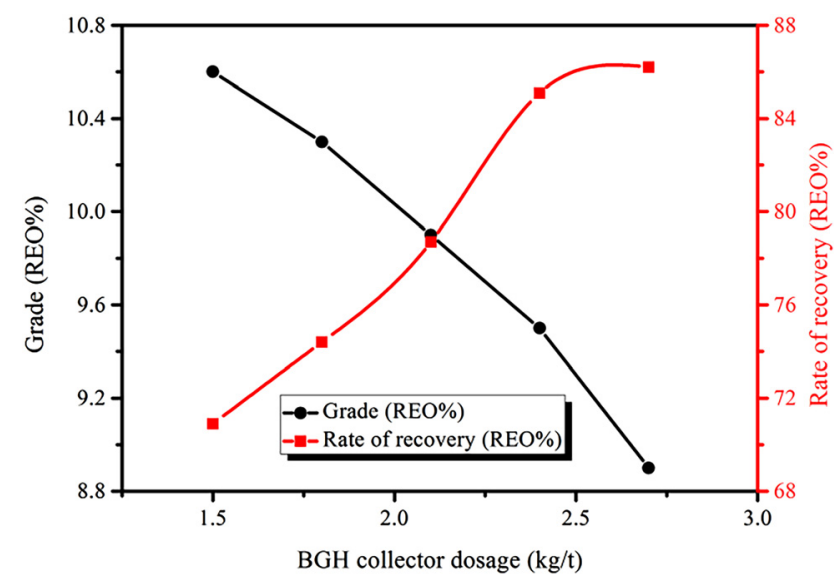

Figure 6: Relationship between amount of BGH collector agent and RE coarse selection index (Conditions: water glass dosage of $2.4 \mathrm{~kg} / \mathrm{t}$ and NXJ dosage of $2.5 \mathrm{~kg} / \mathrm{t}$ ).

exhibits good selectivity for RE minerals. Figure 6 shows the relationship between the different dosages of collector BGH and the RE selectivity. As the amount of collector was increased, the grade of RE coarse concentrates gradually decreased, and the recovery rate increased gradually.

During the RE flotation process, the collectors concentration in the pulp were continuously increased because the continued addition of the collectors, and the absorbed amount of the collectors were also increased, finally leading to that some RE mineral linked with gangue floated on the top and further entered in RE coarse concentrate, which decreased the grade of the RE coarse concentrate, and finally the recovery rate was increased. For the RE coarse concentrate, the optimum condition is to get a higher recovery rate, and then to get a higher grade. Therefore, when the collector dosage is $2.4 \mathrm{~kg} / \mathrm{t}$, the RE coarse concentrate with $\mathrm{RE}$ grade of $9.5 \%$ and recovery rate of $85.1 \%$ can be obtained.

\subsubsection{Tests on the stability of RE flotation}

Using the optimal test conditions with a water glass dosage of $2.4 \mathrm{~kg} / \mathrm{t}$, NXJ dosage of $2.5 \mathrm{~kg} / \mathrm{t}$, and BGH dosage of $2.4 \mathrm{~kg} / \mathrm{t}$, RE flotation stability tests are carried out with a coarse selection operation and three additional selection operations. The weighted average results of the stability tests are shown in Table 4. An RE concentrates with a yield of $3.8 \%$, RE grade of $51.9 \%$, and a recovery rate of $50.1 \%$ can be obtained with flotation separation of iron tailings. In the selection process, the RE grade of middling 3 is higher than that of ore feeding, and that of middling 2 is close to that of ore feeding, so they can be returned to the mine again. The middling 1 and RE flotation tailings are enriched to $85.7 \%$ iron; the two parts of mixed RE grade are $1.2 \%$, and TFe grade is $17.2 \%$. Middling 1 and $\mathrm{RE}$ in tailings of RE minerals consist mainly of intergrowths, as observed through microscopic examination. Hence, the two parts can be mixed and used as raw materials for the recovery of iron minerals.

\subsection{Second recovery of iron}

\subsubsection{Influence of magnetic separation on iron selection}

The use of the middling 1 and Bayan Obo tailings as the feed material for iron separation and the low grade of TFe necessitate that the iron minerals be recovered using strong magnetic separation. This recovery results in a considerable enrichment of TFe grade in the flotation, and subsequently, the iron concentrate is obtained by positive flotation of the magnetite concentrate. Magnetic separation tests are carried out with a magnetic field strength of $636.8 \mathrm{kA} / \mathrm{m}$, and the test results for strong magnetic separation are shown in Table 5. Crude concentrate with a grade of $30.8 \%$ and a recovery rate of $60.7 \%$ were obtained by magnetic selection. The iron grade of the flotation is improved, and the tailings with a production rate of $65.5 \%$ are thrown away. This process drastically reduces the amount of flotation slender and creates conditions allowing the collection of qualified iron concentrate with positive iron flotation.

\subsubsection{Influence of flotation on iron selection index}

In these experiments, the collector is the fatty acid collector GXY, ammonium fluorosilicate, which is used to regulate

Table 4: Results of RE flotation stability test.

\begin{tabular}{lrrrrr}
\hline Items & Yields (\%) & Grade (REO \%) & Recovery rate (REO \%) & Grade (TFe \%) & Recovery rate (TFe \%) \\
\hline RE concentrate & 3.8 & 51.9 & 50.1 & 1.9 & 0.4 \\
Middling 3 & 8.6 & 7.6 & 16.8 & 9.2 & 15.7 \\
Middling 2 & 9.0 & 3.8 & 8.8 & 21.5 & 8.9 \\
Middling 1 & 26.4 & 1.6 & 10.7 & 15.1 & 35.9 \\
RE flotation tailings & 52.3 & 1.0 & 13.7 & 15.8 & 49.8 \\
Feedings & 100.0 & 3.9 & 100.0 & & 100.0 \\
\hline
\end{tabular}


Table 5: Results of strong magnetic tests.

\begin{tabular}{lrrr}
\hline Items & $\begin{array}{r}\text { Yield } \\
(\%)\end{array}$ & $\begin{array}{r}\text { Grade } \\
\text { (TFe \%) }\end{array}$ & $\begin{array}{r}\text { Recovery rate } \\
\text { (TFe \%) }\end{array}$ \\
\hline $\begin{array}{l}\text { Strong magnetic separation } \\
\text { coarse concentrate }\end{array}$ & 34.5 & 30.8 & 60.7 \\
$\begin{array}{l}\text { Strong magnetic separation } \\
\text { tailings }\end{array}$ & 65.5 & 10.5 & 39.3 \\
Feedings & 100.0 & 17.5 & 100.0 \\
\hline
\end{tabular}

the $\mathrm{pH}$ of the pulp, and the added amount directly affects the charge on the mineral particles surface in the pulp. Using the GXY collector with a dosage of $1.2 \mathrm{~kg} / \mathrm{t}$ as an optimal collector, the relationships between ammonium fluorosilicate and iron coarse selection criteria are shown in Figure 7. When ammonium fluorosilicate is added, the pulp becomes acidic. The $\mathrm{pH}$ value of the pulp gradually decreases, and the zeta potential of the hematite surface gradually becomes increasingly negative with the addition of increasing amounts of ammonium fluorosilicate (Mei et al. 2005), which facilitates the separation of iron minerals and gangue minerals. This is consistent with the gradual increase in the grade of concentrate and the gradual decrease in the recovery rate of the coarse ore concentrate. A high grade and high recovery rate for iron coarse concentrates are obtained when the dosage of ammonium fluorosilicate is $2.2 \mathrm{~kg} / \mathrm{t}$, and the tests shown below prove that a dosage of $2.2 \mathrm{~kg} / \mathrm{t}$ ammonium fluorosilicate constitutes the optimal condition.

\subsubsection{Iron flotation stability test}

Using an ammonium fluorosilicate dosage of $2.2 \mathrm{~kg} / \mathrm{t}$ and a GXY collector dosage of $1.2 \mathrm{~kg} / \mathrm{t}$, the iron positive floating

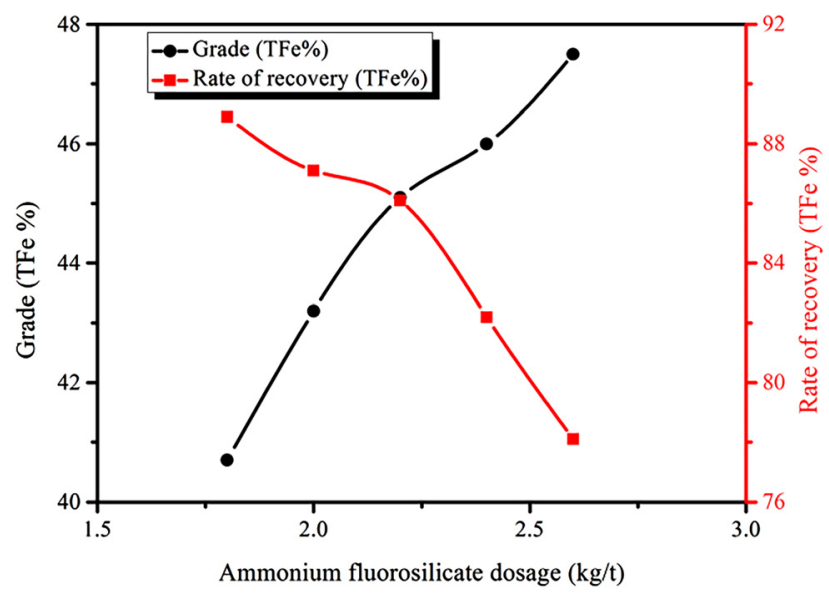

Figure 7: Relationship between the amount of ammonium fluorosilicate and iron coarse selection index. stability tests were carried out with a coarse selection and a second selection. The weighted average results of the stability tests are shown in Table 6 . The iron concentrates, with a yield of $20.8 \%$, a TFe grade of $64.3 \%$, and recovery rate of $43.5 \%$, were obtained by flotation separation of iron concentrate. The TFe grade of middling 1 is $28.3 \%$, which was close to feedings with $30.8 \%$. In the closed circuit experiment, middling 1 could be returned to feed ore for ore concentration. The TFe grade of middling 2 is $48.1 \%$, which was close to iron concentrate with $43.5 \%$. Therefore, middling 2 could be returned to middling 1 for ore concentration in closed circuit test.

\subsection{Mechanism of recovery of rare earth and iron}

\subsubsection{The action mechanism of BGH collector and bastnaesite}

In order to study the action mechanism of bastnaesite and BGH collector, firstly, the FTIR analyses of BGH collector and bastnaesite were carried out. At the same time, bastnaesite interacted with BGH collector, and the products were also analyzed by FTIR. The three spectra in Figure 8 are the IR spectra of BGH collector, bastnaesite, and bastnaesite with BGH collector, respectively.

The characteristic absorption peaks for the main functional groups are shown in Figure 8. By comparing the IR spectra before and after the addition of the collector, it was found that peaks at 2923, 2856, 1604, and $1121 \mathrm{~cm}^{-1}$ appeared in the IR spectra after the addition of the agent (Wang et al. 2020; Xiong et al. 2018; Xu et al. 2019). The positions of these bands were basically unchanged, which indicated that some organic components were adsorbed on the bastnaesite surface. The characteristic absorption peaks at 1604 and $1121 \mathrm{~cm}^{-1}$ increased in intensity in the third spectrum, which were likely due to the $\mathrm{C}=\mathrm{O}$ and -C-O- groups of the $\mathrm{BGH}$ collector, respectively. In the black curve, they appeared at 1638 and $1143 \mathrm{~cm}^{-1}$, which were characteristic positions for the RE collector.

Table 6: Results of iron flotation stability test.

\begin{tabular}{lrrr}
\hline Items & Yield (\%) & Grade (TFe \%) & $\begin{array}{r}\text { Recovery } \\
\text { rate (TFe \%) }\end{array}$ \\
\hline Iron concentrate & 20.8 & 64.3 & 43.5 \\
Middling 2 & 8.6 & 48.1 & 13.4 \\
Middling 1 & 29.8 & 28.3 & 27.3 \\
RE flotation tailings & 40.8 & 12.0 & 15.9 \\
Feedings & 100.0 & 30.8 & 100.0 \\
\hline
\end{tabular}




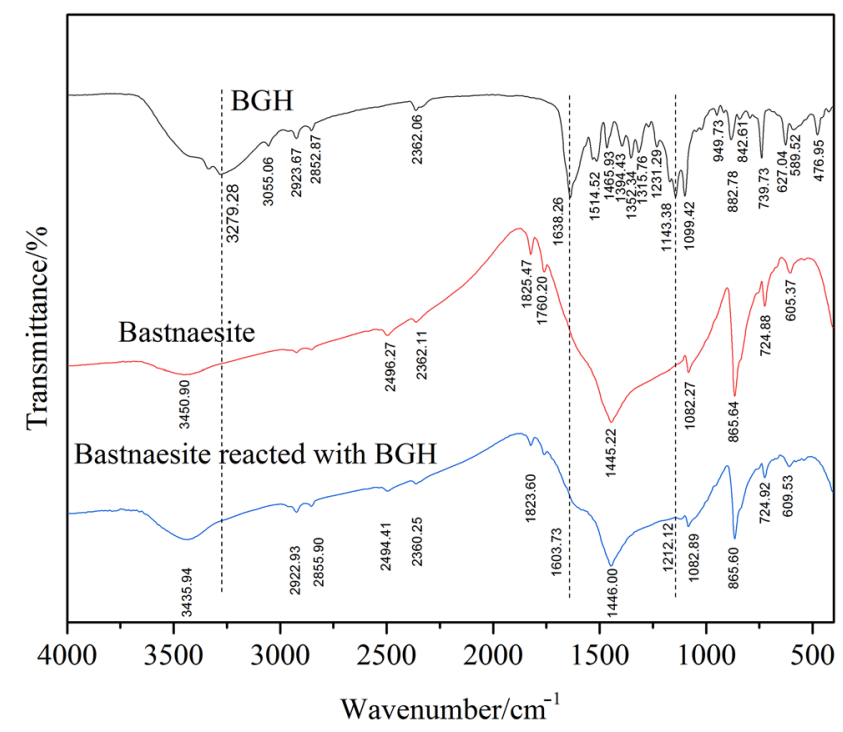

Figure 8: Infrared spectra of BGH and bastnaesite.

In Figure 8, the BGH represented the BGH collectors. From the Figures, the wavenumber of $3279 \mathrm{~cm}^{-1}$ on the IR spectra of the BGH collectors belonged to the $-\mathrm{OH}$ peaks, however, this peak disappeared on the IR spectra of the bastnaesite after functioned with the BGH collectors, indicating that the $-\mathrm{OH}$ groups were replaced by $\mathrm{H}$ groups. These results all indicated that the chemical absorption of the BGH collectors on the bastnaesite occurred, and the collectors were combined with the bastnaesite successfully.

The X-ray photoelectron spectra for bastnaesite and bastnaesite treated with collectors were also obtained, and the results are shown in Figure 9. Ce, La, C, O, F, and other elements were contained in the bastnaesite minerals. In addition, there were small amounts of $\mathrm{Fe}, \mathrm{Ca}$, and $\mathrm{P}$ contaminants on the surface and this was mainly caused by the presence of minerals containing iron ore and calcium in the bastnaesite. A comparison of spectra obtained before and after the addition of RE collector showed that the C1s peak was significantly enhanced, while the intensities of the

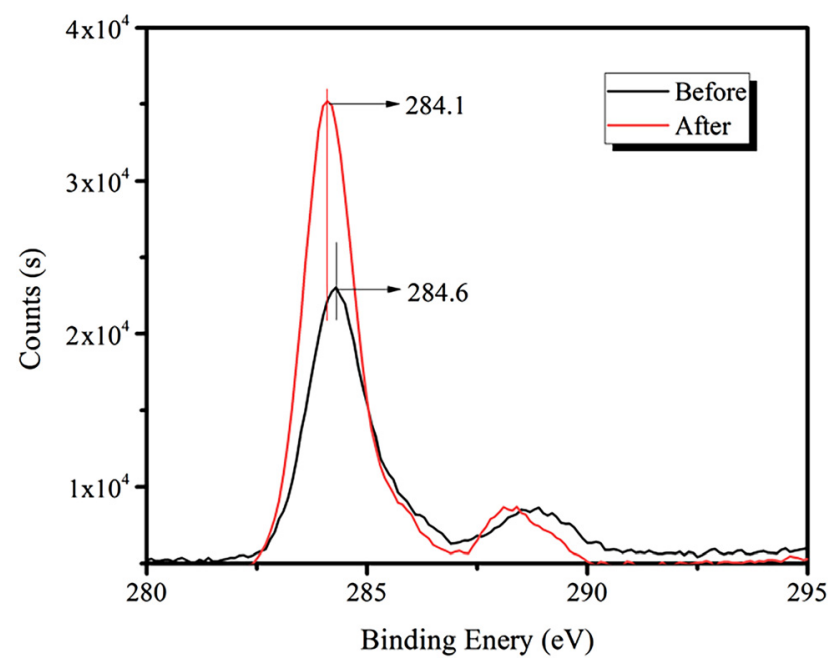

Figure 10: XPS spectra of C1s before and after the addition of the RE collector.

spectral peaks for O1s, Ce, La, and other elements were significantly weakened. After the addition of RE collector, the peak intensity for C1s increased from 37.3 to $57.5 \%$, and the peaks for O1s, Ce3d5, La3d5, and F1s decreased from $38.9,1.7,0.6$, and 6.7 to $29.3,1.6,0.4$, and $4.2 \%$, respectively. Thus, the RE collector was confirmed to be adsorbed onto the bastnaesite surface.

Figure 10 shows that the strength of the C1s peak of bastnaesite increases significantly after the addition of $\mathrm{RE}$ collector, and its binding energy shifts to a lower position; this changed from 284.6 to $284.1 \mathrm{eV}$, with a decrease of $0.5 \mathrm{eV}$.

Figure 11 shows that the strength of the 01s peak for bastnaesite is diminished after addition of the RE collector, and the binding energy is shifted to lower energy, which changed from 531.6 to $531 \mathrm{eV}$.

Figure 12 demonstrates that the strength of the Ce3d peak for bastnaesite is diminished after the addition of the $\mathrm{RE}$ collector, and the binding energy is shifted from 885 to $884.4 \mathrm{eV}$ (a decrease of $0.6 \mathrm{eV}$ ).

Figure 13 shows that the strength of the La3d peak for lanthanum bastnaesite is diminished after the addition of (a)

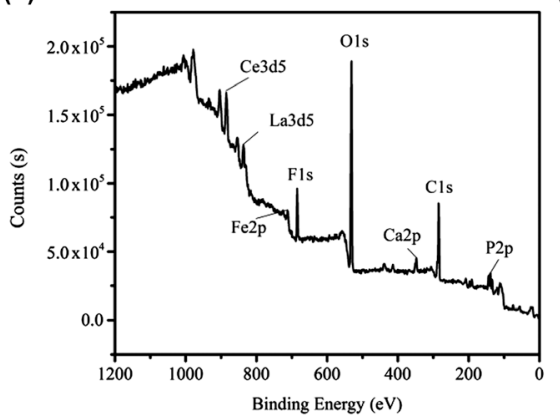

(b)

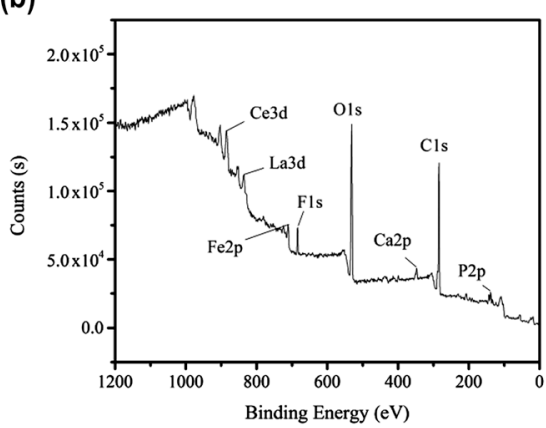

Figure 9: (a) XPS spectra of bastnaesite and (b) bastnaesite with a collector. 


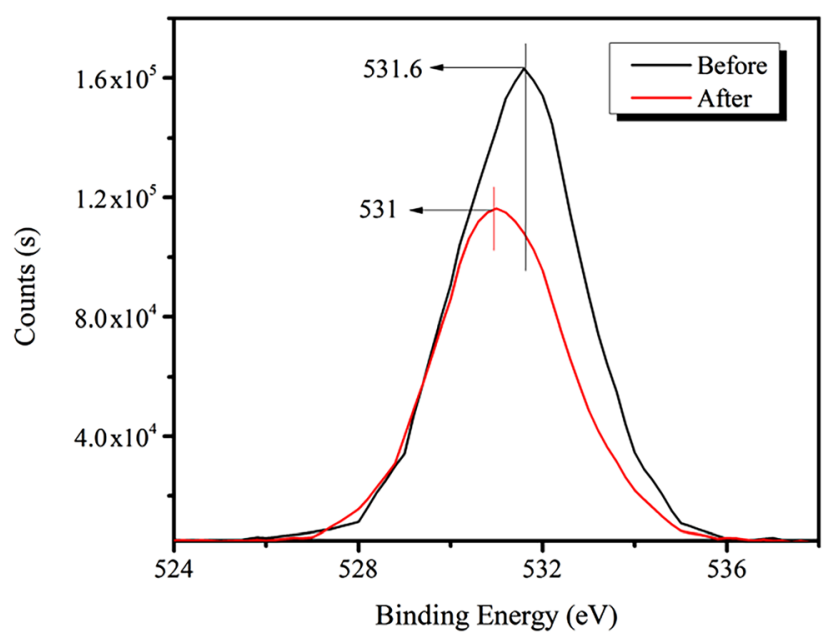

Figure 11: XPS spectra of 01s peak before and after adding RE collector.

$\mathrm{RE}$ collector, and the binding energy is shifted from 836.6 to $836 \mathrm{eV}$ (a decrease of $0.6 \mathrm{eV}$ ).

Figure 14 illustrates that the strength of the $\mathrm{C} 1 \mathrm{~s}$ peak for bastnaesite increases significantly after the addition of the $\mathrm{RE}$ collector, and the binding energy shifts from 684.8 to $684.2 \mathrm{eV}$ (a decrease of $0.6 \mathrm{eV}$ ).

After interaction with the RE collector, the Ce3d, La3d, C1s, O1s, F1s peaks, and other elements existed in the bastnaesite deposit, all exhibit shifts to lower energies; these are reduced by more than $0.3 \mathrm{eV}$, indicating a chemical reaction. These results confirms that the RE collector is chemically adsorbed onto the $\mathrm{Ce}, \mathrm{La}$, and other particles. This is mainly because $\mathrm{Ce}$ and La atoms gain electron density when bind with oxygen atoms, resulting in

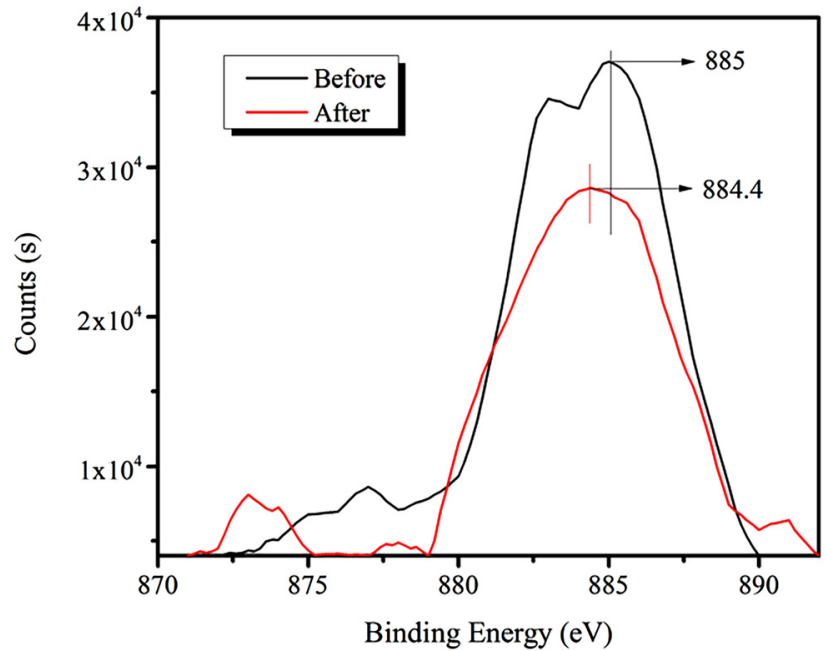

Figure 12: XPS spectra of Ce3d peak before and after the addition of RE collector.

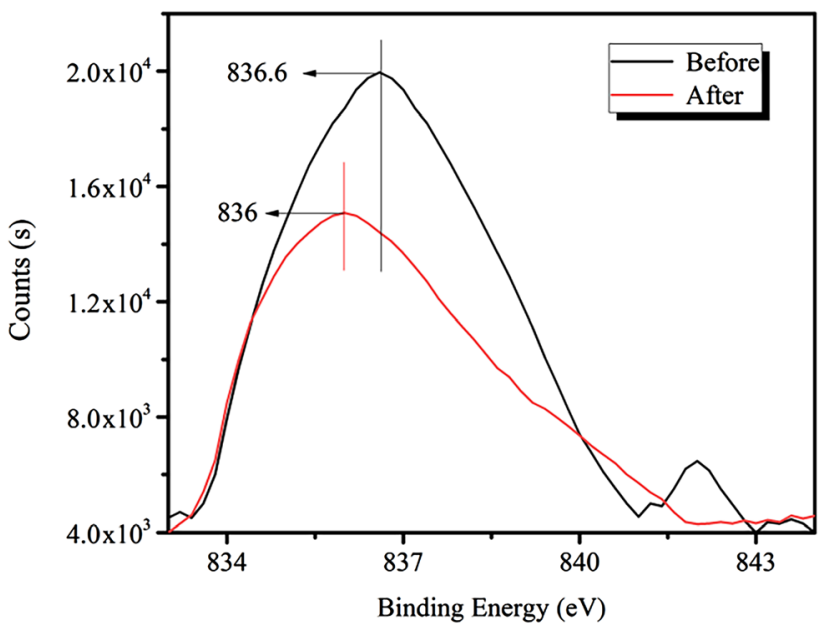

Figure 13: XPS spectra for the La3d peak before and after the addition of the RE collector.

increased cloud density of the Ce3d orbital electron and decreased binding energy. Therefore, it can be speculated that Ce or La particles in cerium fluorocarbon and oxide particles react with the RE collectors to form stable fivemembered chelate rings, and the reaction equation is described in Figure 15.

\subsubsection{The action mechanism of the GXY collector and iron minerals}

Since the amount of hematite in the iron flotation mineral separation was very low, and its particle size was fine. Therefore, it was very hard to obtain the qualified iron concentrate when using the single collector. In the

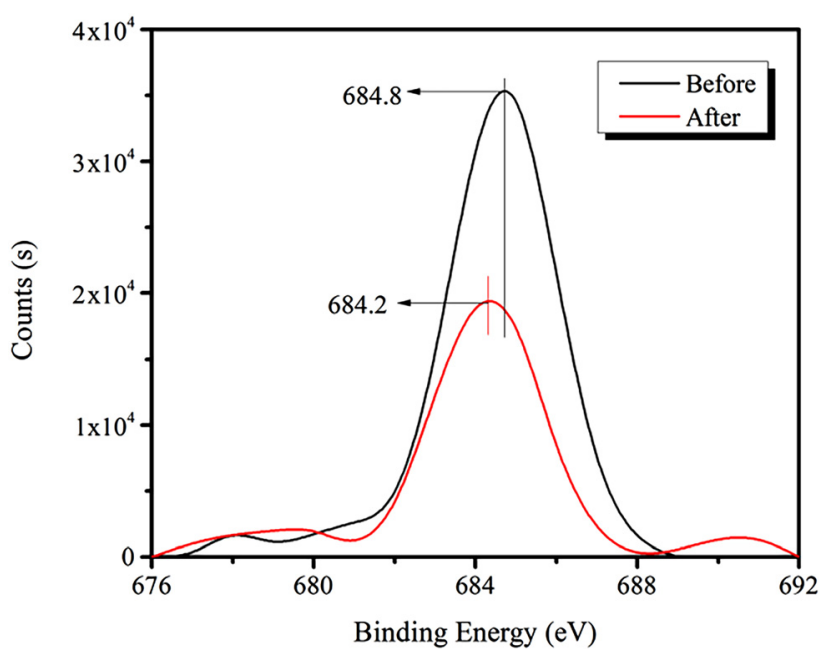

Figure 14: XPS spectra of F1s peak before and after the addition of the RE collector. 
<smiles>CC(C)(C)OC(=NO)c1cc2ccccc2cc1OC(C)(C)C</smiles>

Figure 15: The reaction equation of $\mathrm{Ce}$ or La particles in cerium fluorocarbon and oxide particles reacted with RE collectors. selecting flotation of iron, the ammonium fluosilicate as the pulp regulators, while used the GXY as the collector for iron minerals. The GXY was referred to the mixture of sodium oleate and oxidized paraffin soap.

In the cases of the collecting mechanisms of sodium oleate and iron minerals, the researchers of mineral separation did a lot of studies. Yap et al. (Yap et al. 1981) further provided five kinds of microscale form about the function between sodium oleate and hematite based on the studies of other researchers: (1) the electrostatic interaction, (2) double bond interaction, (3) the formation of complex compound, (4) hydrogen-bond interaction, (5) oleate ions. By using the IR spectra, Liu et al. (Liu et al. 2018b) have found that chemical absorption occurred between the sodium oleate and iron minerals in the $\mathrm{pH}$ scope of $7.5 \sim 9.4$, and the ferric oleate was formed. In the $\mathrm{pH}$ of 6.8 , not only the chemical absorption occurred, but also the physical absorption. Kulkarni et al. (Kulkarni and Somasundaran 1980) found that the iron minerals and oleate ions produced chemical absorption after the function of iron mineral and sodium oleate, and mainly formed the ferric oleate compound. The collecting action of sodium oleate on hematite was dependent on the co-functioned results of physical and chemical absorptions.

During the floatation selecting process of hematite, ammonium fluosilicate was used as pulp regulators, which not only adjusted the $\mathrm{pH}$ value of pulp, but also had selecting inhibition to silicate minerals. Sodium fluosilicate would form tiny colloidal particle in the acid medium, which would selectively absorb on the gangue mineral (such as silicate), finally making it hydrophilic and therefore it was further inhibited (Feng et al. 2015).

Based on the previous studies, in the flotation selecting process of hematite, the ore pulp was acid with the addition of ammonium fluosilicate, and the $\mathrm{pH}$ of ore pulp was gradually decreased (Lan et al. 2019; Liu, Qiu, and Sun 2019a; She et al. 2017; Song et al. 2018). Since the hematite surface continuously absorbed $\mathrm{H}^{+}$, the surface $\zeta$ potential

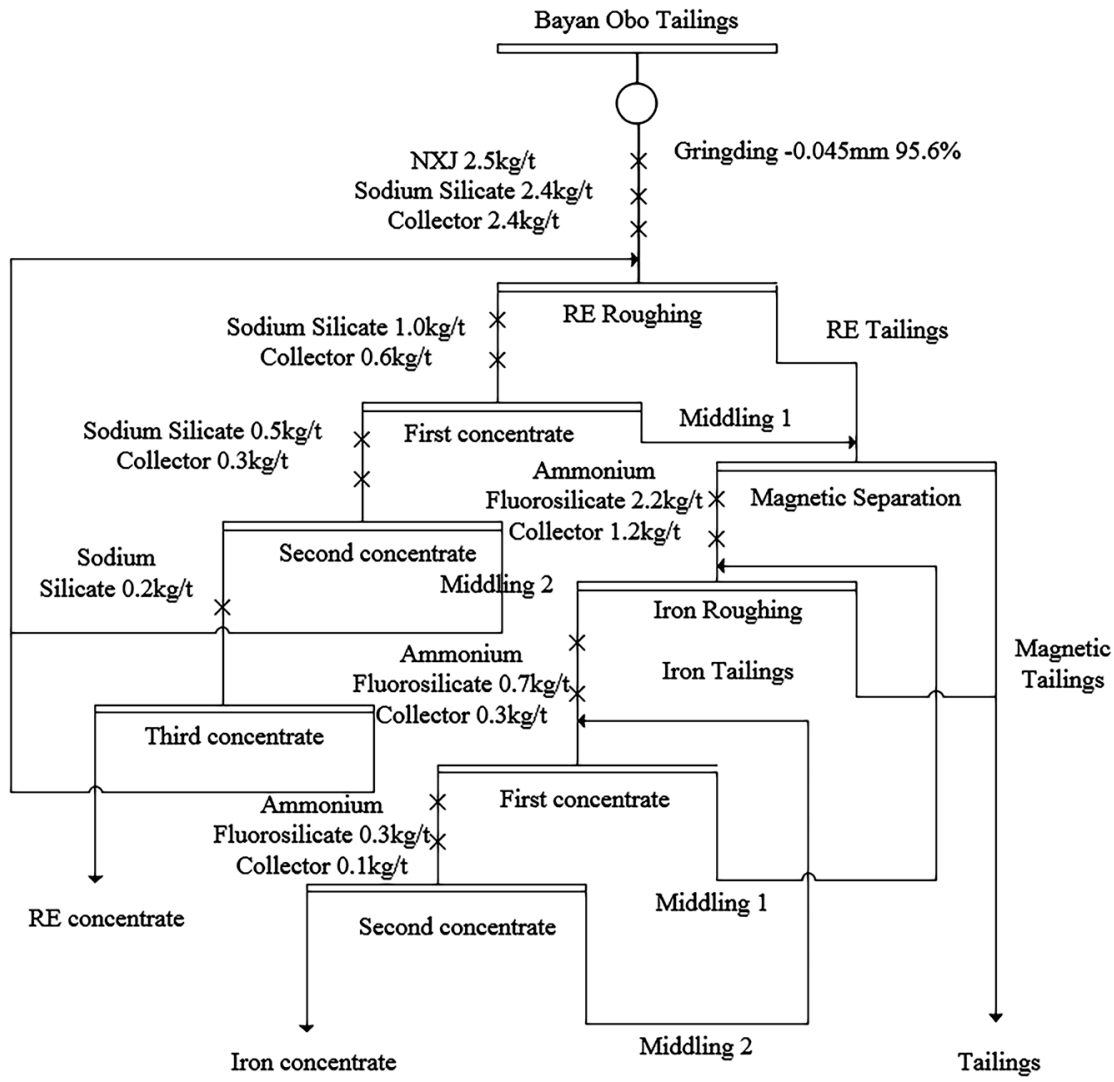

Figure 16: Flowchart for recycling RE and iron from Bayan Obo tailings. 
was gradually turn positive. The absorption amounts of oleate ions, saturated fatty acid ions and other kinds of unsaturated fatty acid ions in the GXY collectors on the hematite surface were gradually increased, and under this condition, the sodium oleate and fatty acid such as oxidized paraffin soap had chemical absorption with hematite, and formed ferric fatty acid, the reaction equations were presented as follow:

Fe-OH (the absorbed water on hematite surface)

$$
\begin{aligned}
& +\mathrm{RCOOH} \text { (fatty acid) } \\
& =\mathrm{Fe}-\mathrm{OH} \cdot \mathrm{RCOOH}
\end{aligned}
$$

Fe-OH $\cdot$ RCOOH $=$ FeOOCR (the absorbed fatty acid ions on hematite surface) $+\mathrm{H}_{2} \mathrm{O}$

\subsection{Optimal process parameters for closed- circuit experiment}

Using the previously established optimal conditions for reagents, grinding fineness, and iron flotation reagent system, a closed-circuit test of Bayan Obo tailings was carried out with the processes of grinding, RE flotation, strong magnetic separation and positive flotation of iron. Starting with a Bayan Obo tailings exhibited a RE grade of $3.8 \%$ and TFe grade of $15.3 \%$, and it proved to be possible to generate a RE concentrate with a yield of $4.7 \%$, an RE grade of $50.3 \%$, and a recovery rate of $61.6 \%$, and an iron ore concentrate with a yield of $7.2 \%$, a TFe grade of $64.0 \%$, and a recovery rate of $30.0 \%$. A flow chart for the comprehensive recovery of $\mathrm{RE}$ and iron from the Bayan Obo tailings is shown in Figure 16.

\section{Conclusions}

(1) The majority of the RE and iron minerals that can be recycled in the tailings are interrelated, so usable $\mathrm{RE}$ concentrate and iron concentrate must be obtained by fine grinding. The RE collectors exhibited chemical reactions with $\mathrm{Ce}$, La, and other particles, with which they formed stable five-membered cyclic chelates.

(2) After adopting the new process of ore dressing through grinding, RE flotation, strong magnetic separation, and positive flotation, treatment of Bayan Obo tailings resulted in satisfactory dressing and comprehensive recycling of ultrafine RE minerals and hematite. The reagent combination in this process is broadly applicable for the dressing of RE and iron from Bayan Obo tailings.
(3) Moreover, by controlling the slurry dispersion technology, secondary recovery of $\mathrm{RE}$ and iron from the tailings of RE was achieved. The RE grade was $50.3 \%$, with a recovery rate of $61.6 \%$, and the TFe grade was $64.0 \%$ with a recovery rate of $30.0 \%$, constituting significant improvements in the levels of resource utilization.

Author contribution: All the authors have accepted responsibility for the entire content of this submitted manuscript and approved submission.

Research funding: None declared.

Conflict of interest statement: The authors declare no conflicts of interest regarding this article.

\section{References}

Abaka-Wood, G. B., J. Addai-Mensah, and W. Skinner. 2018a. “A Study of Selective Flotation Recovery of Rare Earth Oxides from Hematite and Quartz Using Hydroxamic Acid as a Collector." Advanced Powder Technology 29: 1886-99.

Abaka-Wood, G. B., M. Zanin, J. Addai-Mensah, and W. Skinner. 2018b. "The Upgrading of Rare Earth Oxides from Iron-Oxide Silicate Rich Tailings: Flotation Performance Using Sodium Oleate and Hydroxamic Acid as Collectors." Advanced Powder Technology 29: 3163-72.

Abaka-Wood, G. B., K. Quast, M. Zanin, J. Addai-Mensah, and W. Skinner. 2019a. "A Study of the Feasibility of Upgrading Rare Earth Elements Minerals from Iron-Oxide-Silicate Rich Tailings Using Knelson Concentrator and Wilfley Shaking Table.” Powder Technology 344: 897-913.

Abaka-Wood, G. B., M. Zanin, J. Addai-Mensah, and W. Skinner. 2019b. "Recovery of Rare Earth Elements Minerals from Iron Oxide-Silicate Rich Tailings - Part 2: Froth Flotation Separation.” Minerals Engineering 142: 1-12.

Abaka-Wood, G. B., S. Fosu, J. Addai-Mensah, and W. Skinner. 2019c. "Flotation Recovery of Rare Earth Oxides from Hematite-Quartz Mixture Using Sodium Oleate as a Collector.” Minerals Engineering 141: 1-11.

Avazpour, R., M. Latif, J. Chaouki, and L. Fradette. 2019. “Physical Benefciation of Rare Earth-Bearing Ores by Pickering Emulsification.” Minerals Engineering 144: 1-15.

Feng, B., X. Luo, J. Wang, and W. Pengcheng. 2015. “The Flotation Separation of Scheelite from Calcite Using Acidified Sodium Silicate as Depressant." Minerals Engineering 80: 45-9.

Jordens, A., Y. P. Cheng, and K. E. Waters. 2013. "A Review of the Beneficiation of Rare Earth Element Bearing Minerals." Minerals Engineering 41: 97-114.

Kulkarni, R., and P. Somasundaran. 1980. "Flotation Chemistry of Hematite/oleate System.” Colloids \& Surfaces 1: 387-405.

Kursun, I., M. Terzi, and O. Ozdemir. 2019. “Determination of Surface Chemistry and Flotation Properties of Rare Earth Mineral Allanite." Minerals Engineering 132: 113-20.

Lan, X., J. Gao, Y. Du, and Z. Guo. 2019. “A Novel Method of Selectively Enriching and Separating Rare Earth Elements from Rare-Earth Concentrate under Super Gravity." Minerals Engineering 133: 27-34. 
Liu, C., J. Qiu, and L. Sun. 2018a. "Liquidus and Phase Equilibrium in $\mathrm{CaO}-\mathrm{SiO}_{2}-\mathrm{Nb}_{2} \mathrm{O}_{5}-10 \% \mathrm{La}_{2} \mathrm{O}_{3}$ System." ISIJ International 58: 612-19.

Liu, S., H. Fan, K. Yang, F. F. Hu, B. Rusk, X. Liu, X. C. Li, Z. F. Yang, Q. W. Wang, and K. Y. Wang. 2018b. "Fenitization in the Giant Bayan Obo REE-Nb-Fe Deposit: Implication for REE Mineralization.” Ore Geology Reviews 94: 290-309.

Marion, C., R. Li, and K. E. Waters. 2020. "A Review of Reagents Applied to Rare-Earth Mineral Flotation." Advances in Colloid and Interface Science 279: 1-25.

Mei, G., J. Yu, Y. Ge, and Y. U. Yong-fu. 2005. “Selective Depressive Action of Ammonium Hexafluorosilicate in Flotation Separation of Hematite and Iron-Containing Silicate." Mining and Metallurgical Engineering 25: 24-9.

Owens, C. L., E. Schach, T. Heinig, and M. Rudolph. 2019. "Surface Nanobubbles on the Rare Earth Fluorcarbonate Mineral Synchysite." Journal of Colloid \& Interface Science 552: 66-71.

Ren, J., S. Lu, S. Song, and J. Niu. 1997. "A New Collector for Rare Earth Mineral Flotation.” Minerals Engineering 10: 1395-404.

Sarswat, P. K., M. Leake, L. Allen, M. L. Free, X. Hu, D. Kim, A. Noble, and G. H. Luttrell. 2020. "Efficient Recovery of Rare Earth Elements from Coal Based Resources: a Bioleaching Approach." Materials Today Chemistry 16: 1-17.

She, X., Y. Zhao, F. Feng, and J. S. Wang. 2017. "Reduction Process of Rare Earth Bayan Obo Complex Iron Ore by Carbon Monoxide at 1073-1273 K." Ironmaking \& Steelmaking 44: 1-7.
Song, W., C. Xu, M. Smith, and A. Chakhmouradian. 2018. "Genesis of the World's Largest Rare Earth Element Deposit, Bayan Obo, China: Protracted Mineralization Evolution over Similar To1 b.y." Geology 46: 323-6.

Wang, J., M. Guo, M. Liu, and X. Wei. 2020. "Long-term Outlook for Global Rare Earth Production.” Resources Policy 65: 1-8.

Xiong, W., J. Deng, B. Chen, S. Deng, and D. Wei. 2018. "Flotationmagnetic Separation for the Beneficiation of Rare Earth Ores." Minerals Engineering 119: 49-56.

Xu, C. L., C. B. Zhong, R. Lyu, Y. Ruan, Z. Zhang, and R. Chi. 2019. "Process Mineralogy of Weishan Rare Earth Ore by MLA." Journal of Rare Earths 37: 334-8.

Yap, S. N., R. K. Mishra, S. Raghavan, and D. W. Fuerstenau. 1981. "The Adsorption of Oleate from Aqueous Solution onto Hematite." In Proceedings of Symposium on "Adsorption from Aqueous Solutions", edited by P. H. Tewari, 119-42. Plenum Press.

Zheng, Q., W. Wu, and X. Bian. 2017a. “Investigations on Mineralogical Characteristics of Rare Earth Minerals in Bayan Obo Tailings during the Roasting Process." Journal of Rare Earths 35: 300-8.

Zheng, Q., X. Bian, and W. Wu. 2017b. “Iron Recovery and Rare Earths Enrichment from Bayan Obo Tailings Using Coal- $\mathrm{Ca}(\mathrm{OH})_{2}-\mathrm{NaOH}$ Roasting Followed by Magnetic Separation." Journal of Iron and Steel Research International 24: 147-55. 